Int. J. Morphol.,

30(3):970-978, 2012.

\title{
Lower Third Molar Region
}

\author{
Región del Tercer Molar Inferior
}

\author{
Iván Suazo Galdames
}

SUAZO, I. Lower third molar region. Int. J. Morphol., 30(3):970-978, 2012.

SUMMARY: The lower third molar region is an important region for the odontostomatological practice, since it presents a great amount of pathological processes related to the development and eruption of the third molar; thus having a considerable number of surgical interventions. Despite its importance, this region is not accounted for in anatomical terminology nor is it described in topographic anatomy; and in spite of the great number of studies that analyze the surgical anatomy of the region, it is necessary to systematize the description of its boundaries, planes, content, risk elements, anatomical repairs, etc.; therefore, the purpose of the present article is to review the modern concepts related to the surgical anatomy of the lower third molar region and to establish a description based on these concepts.

KEY WORDS: Third molar; Lingual nerve; Inferior alveolar nerve; Retromolar triangle; Retromolar pad; Mandibular canal; Oral surgery.

\section{INTRODUCTION}

The lower third molar region corresponds to an anatomical region located in reference to the lower third molar, as such, it is found in the posterior zone of the oral cavity, between the lower molars and the mandibular ramus, extending medially to the floor of the oral cavity, and laterally up to the oral vestibule. Inferiorly, the region penetrates the skeletal plane constituted by the mandible in the retromolar region. Superiorly, its level varies depending on the level of eruption of the third molar, being able to extend up to the molar occlusal plane.

Thus described, the lower third molar region is related to the gingival-alveolar dental mandible, buccal, parotidmesseteric, paralingual space, submandibular, pterygomandibular, pterygo-pharyngeus and tonsillar regions.

External shape and exploration. The lower third molar region has a cuboidal shape, without precise anatomic boundaries, but rather limits determined by clinical-surgical criteria. It corresponds to a block of structures that incorporate the third molar in its core. Therefore, it includes a mucosal plane, which varies considerably depending on the degree of impaction or semi-impaction of the molar, and the development presented by pterygomadibular ligament, which swells up the posterior wall of the region.
The shape of the region is very little modified in the different oral functions. In an individual with a maximum oral opening, the elevation of the mucosa produced by the tension of the pterygomandibular ligament can be clearly seen, giving the upper face of the region a triangular aspect. The movements of the soft palate do not modify the shape of this face.

When the individual has his oral cavity closed, the exploration of the lower third molar region can be performed through digital inspection, the finger moves against the vestibular surface of the molars. In this position, the region participates in the construction of an important space, the coronoid space or coronomaxillary space, which corresponds to the space between the anterior border of the mandibular ramus and the last molars in occlusion (Fig. 1) (Arbree et $a l ., 1987)$. The index finger can be easily introduced in the coronoid space; in this position it is possible to feel, laterally, the independent activity of the superficial and deep fascicles of the masseter muscle; medially, we enter the oral cavity itself; upwards, we may palpate the mucosa lining the lower portion of the maxillary tubercle and the so called hamular notch, and downwards we can palpate the mucosa of the upper surface of the lower third molar region, where normally a mucous pad, called retromolar pad, develops. The coronoid space has clinical use for the introduction of a probe for feeding in case of an intermaxillary fixation. 


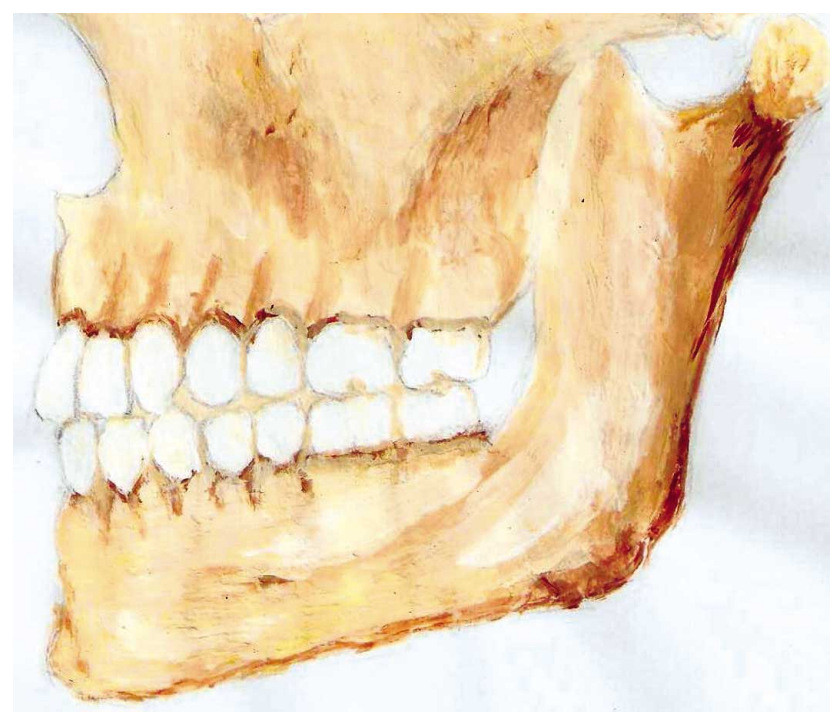

Fig. 1. Scheme of the construction of the coronoid space and its relation to the lower third molar region.

The forensic inspection of the lower third molar region is difficult to perform due to the rigidity of the corpse; in these cases, the bilateral horizontal section of the masseter muscle turns out to be quite useful facilitating the oral opening, which is the procedure recommended for the performance of an oral autopsy (Nakayama et al., 1998).

The shape of the region is modified considerably during the course of pathological processes that frequently affect the region, some affecting the form of the mucosa, such as third molar pericoronitis and the pericoronal abscess, or deforming the underlying bone structures, such as dentigerous cyst, keratocysts, ameloblastomas, etc., or the ectopic position of the molar.

Boundaries. The boundaries of the lower third molar region are functional to the surgical and exploratory procedures, which are performed in the region, these are:

Anterior boundary: Coronal plane which goes along the mesial surface of the lower second molar including the mucoperiosteum and the skeletal plane of the region.

Posterior boundary: Coronal plane that goes along $1 \mathrm{~cm}$ back of the anterior border of the mandibular ramus.

Lateral boundary: Parasagittal plane that runs along $1 \mathrm{~cm}$ tangent to the most lateral portion of the mandible at the level of the mandibular angle.

Medial boundary: Parasagittal plane that runs $1 \mathrm{~cm}$ from the bone plane of the alveolar process at the level of the lower third molar.
Upper boundary: Horizontal plane that runs along the superior molar occlusal plane.

Lower boundary: Plane that runs at the level of the inferior cortical bone of the mandibular canal where it crosses the third molar region.

Forming Planes. Considering an individual with an oral cavity at its maximum opening, the lower third molar region presents three forming planes: The mucosa, the muscular plane and the skeletal plane.

1. Mucosa Plane: According to the boundaries described, the mucosa can be seen through direct inspection in the superior, posterior, medial and lateral surfaces; the anatomy of the mucosa varies depending on the surface observed. Due to its continuity, we will describe the superior and posterior surfaces together, and independently, the lateral and medial surfaces.

a) Posterosuperior surface (Fig. 2): The mucosa of the posterosuperior surface of the region has a quadrilateral shape, it extends forming an inclined plane that has a slight anterior concavity. It can be divided in two triangular zones because of the elevation of the pterygomandibular ligament, a superolateral triangle and an inferomedial one.

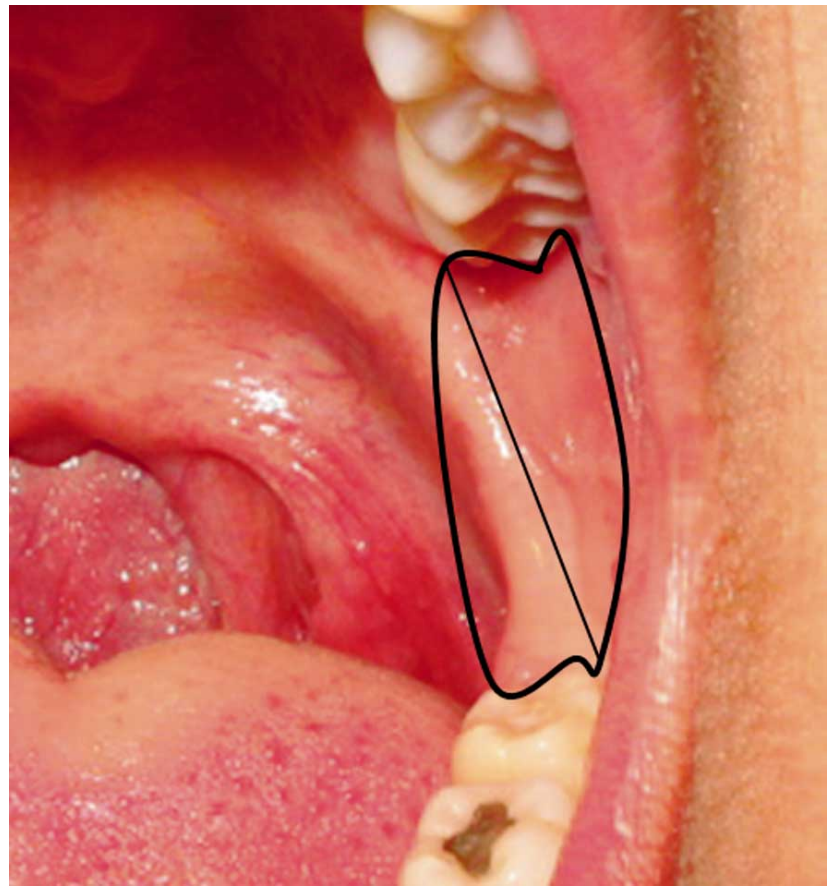

Fig. 2. Photograph of the oral cavity showing on the left, the approximate boundaries of the region mucosa posterosuperior wall; the subdivision in the anaesthetic triangle and a retromolar one may be seen. 
The superolateral triangle, or anaesthetic, presents a characteristic lining mucosa; it has a bright red aspect and it is a continuity of the mucosa that lines the bucca. It is depressible upon digital inspection and its shape is modified by the activity of the underlying buccinator muscle. In this region, the puncture site of the anesthetic technique directed to the mandibular lingula is found which seeks to anesthetize the buccal, lingual and lower alveolar nerves (Khoury \& Townsend, 2011).

The inferomedial or retromolar triangle present a slightly thicker mucosa than that of the anaesthetic triangle, it has a pale and bright look, and its shape outstands for the presence of an anteroposteriorly elongated elevation which widens with the proximity of the second molar and corresponds to the pyriform papilla (retromolar pad). In this zone, the mucosa is depressible and its connection to the skeletal plane is more relaxed than in other zones of the lower third molar region. The pyriform papilla has a length of $11.2 \mathrm{~mm}$ and a mean maximum transverse diameter of 7.94 ; its shape is mainly oval or piryform in a $53.1 \%$, while it presents itself rounded in a $29.6 \%$, and triangular in a 17.3\% (López et al., 2008). Histologically, it corresponds to a lining epithelium with varying quantities of parakeratinization (McCrorie \& Hall, 1965). The pyriform papilla is important in clinical prosthetics since it is considered a stable landmark for the determination of the occlusal plane in edentulous patients (Celebic et al., 1995; Ogawa et al., 1996); additionally, the pyriform papilla participates in the posterior sealing of the mandibular prosthesis, being fundamental in the stability of the apparatus (Taieb \& Carpentier, 1989). For Suazo et al. (2008a), the pyriform papilla is the puncture site for the anaesthetic technique directed to the lower alveolar nerve via the retromolar triangle; the characteristics of the mucosa, its capability of stretching and low vascularization allow a safe puncture in patients carriers of blood dyscrasias.

The zone of the pyriform papilla presents a submucosa in which minor salivary glands are found that group together forming continuous chains with the palatine glands. We can also find some fascicles of the bucciator muscle, temporal and occasionally medial pterygoid (McCrorie \& Hall; Abe et al., 1997).

For the surgery of the third molar, the incision starts at the vertex of the retromolar triangle, moving in contact with the bone plane up to the gingival margin of the second molar (Sandner, 2007). After the surgical extraction of the lower third molar, the pyriform papilla usually forms a depression in which the mucosa is thickened and strongly adhered to the deep planes. There are no studies that assess the effect of post-surgery modeling of the pyriform papilla either in the prosthetic aspects or in the execution of the anaesthetic technique described for this zone.

b) Lateral surface: The mucosa of the lateral surface of the lower third molar region is strongly adhered to the skeletal plane forming a mucoperiosteum. In this region, the mucosa is continued with the lining of the alveolar process to the anterior and laterally it is found forming the most posterior portion of the floor of the inferior oral vestibule.

c) Medial surface: The mucosa of the medial surface is intimately adhered to the underlying bone; in this zone the mucosa reaches its minimum thickness. It continues to the interior with the rest of the lingual lining of the alveolar process, while downwards it reflects and then it becomes a continuity of the mucosa of the floor of the oral cavity. Posteriorly, the mucosa of this surface becomes a continuity of the one that lines the anterior surface of the anterior pillar of the soft palate.

2. Muscle Plane: Within the boundaries of the region, we can find three principal muscles, these are: The Bucciator muscle, the upper constriction muscle of the pharynx and the distal fascicle of the temporal muscle. In addition, the medial pterygoid and the palatoglossal muscles can extend up to the region of the lower third molar.

a) The buccinator muscle forms the muscular wall of the aneaesthetic triangle region of the posterosuperior surface of the mucosa; in this region the muscle is being inserted in the pterygomandibular ligament and its fibers are laid out in a slanted way inferolaterally directed to its point of origin in the retromolar fossa of the mandible. It is important to point out that this muscle has a sheath of connective tissue, the fascia o the buccinator muscle. Due its position, this muscle and its fascia must be crossed with the needle during the anaesthetic technique to the mandibular lingula.

b) The upper constrictor muscle of the pharynx forms part of the lower third molar region only in two of its portions, the buccopharyngeal and the mylo-pharyngeal. The buccopharyngeal portion constitutes the muscle wall of the posterior portion of the inferomedial triangle of the region's posterosuperior surface and it extends from the pharyngeal raphe up to the pterygopharyngeal ligament. The mylopharyngeal portion goes from the pharyngeal raphe to the posterior section of the mylohyoid line of the mandible.

Between the buccinator muscles and the pharynx upper constrictor extends the pterygomandibular ligament, a very important tendon formation, strongly palpable that extends from the pterygoid hook to the mylohyoid line of the mandible. This formation is an important landmark for 
the location of the anaesthetic triangle, in some occasions its development is so important that it can be mistaken for the anterior border of the mandibular ramus.

d) The distal fascicle of the temporal muscle goes downwards along the temporal ridge and ends inserted in the medial lip of the retromolar triangle. This muscle portion seems to have a relevant role in the shape changes of the pyriform papilla.

3. Skeletal plane: The bone plane of the lower third molar region is constituted by the posterior zone of the mandible. This is a transition zone between the body and the ramus. Anatomically, it is possible to find a series of relevant formations in the organization of the region, these are: the retromolar triangle, retromolar fossa, lateroalveolar canal and the mylohyoide ridge. Additionally, the thickness of the cortex and the organization of the spongy tissue are modified in the different portions of the region (Fig. 3).

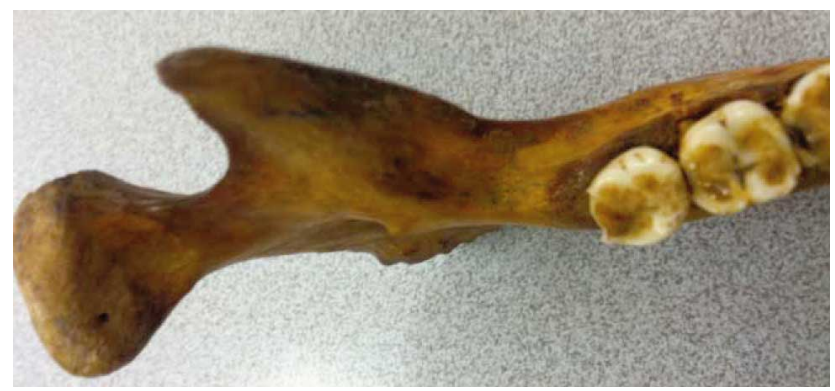

Fig. 3. Photograph of the mandible where the retromolar triangle, retromolar fossa, and lateroalveolar canal may be seen.

a) Retromolar triangle: Classically described as a region in a triangular shape, bordered by the two bifurcation lips of the temporal ridge and the distal surface of the last molar (Figún \& Garino, 2001). This zone is a permanent structure of the mandible, its presence is independent of the existence of dentary pieces, and its shape is not always triangular. Figure 4 shows the most common shapes that the retromolar triangle takes according to Suazo et al., (2007a). It is crossed by a number of variable holes, average 27.1 of small diameter $(0.04-0,25 \mathrm{~mm})$ and 9.5 of greater diameter $(0.25-1.9 \mathrm{~mm})$. These holes allow the passing oframi of the buccinator artery that anastomize with the lower alveolar artery (Kodera \& Hashimoto, 1995) and would allow the diffusion of the anaesthetic solution for the blocking of the lower alveolar nerve by filtration of the retromolar zone (Sandoval et al., 2008; Suazo et al., 2008a). At this level, the mean thickness of the cortex is $1.8 \mathrm{~mm}$ (Suazo et al., 2007a), this dimension, together with the underlying cancellous bone, make the retromolar triangle zone a possible contributor of bone for grafts (Fakhry, 2011).

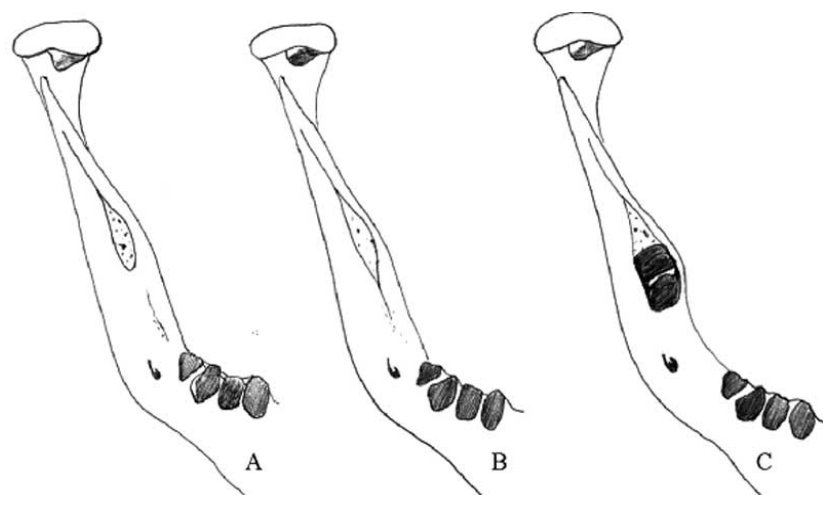

Fig. 4. Most prevalent types of retromolar triangles, according to Suazo et al.,2007a. A. Tapering form 9.16\%; B. Drop form $10.83 \%$; C. Triangular form $80 \%$.

b) Retromolar fossa: It corresponds to a depression located towards the lateral of the retromolar triangle; thus, its medial boundary is the lateral lip of the triangle and its lateral boundary is constituted by the anterior boundary of the mandibular ramus. Towards the anterior, it continues with the lateroalveolar canal. The retromolar fossa allows insertion to the buccinator muscle. The presence of a retromolar foramen located in this fossa has been described (Fig. 5), with a variable prevalence of $12.9 \%$ in the Brazilian population (Suazo et al., 2008b), $19.5 \%$ in the Japanese (Kodera \& Hashimoto) and between $17.3 \%$ and 21,9\% in India (Narayana et al., 2002; Senthil-Kumar \& Kesavi, 2010). From the retromolar foramen, a retromolar canal is originated which carries irrigation and innervation to the structures of the zone, being able to establish communication and anastomosis with the lower alveolar neurovascular axis (Schejtman et al., 1967). The injury of these elements during an extraction surgery of the lower third molar could cause abundant bleeding, postoperatory haematomas (Azaz \& Lustmann, 1973) or alterations in sensitivity, as well as pain and paresthesias (Muto \& Kanazawa, 1997; Petruzzelli et al., 2003).

c) Lateroalveolar canal: Denominated by Figun \& Garino lateroalveolar canal, is not quite a canal, but rather an elongated depression, a line, located on one side of the alveolar process at the level of the lower molars, which extends up to the proximities of the mental foramen. In this zone, the mandible lacks muscular insertions, for which the lateroalveolar canal corresponds to a bare zone of the mandible.

The retromolar fossa and the lateroalveolar canal are clinically important since they correspond to a passing zone for infectious processes originated in the third molar region, called Chompret-L'Hirondel migratory abscesses (Libersa et al., 1982; Peron, 2004). 


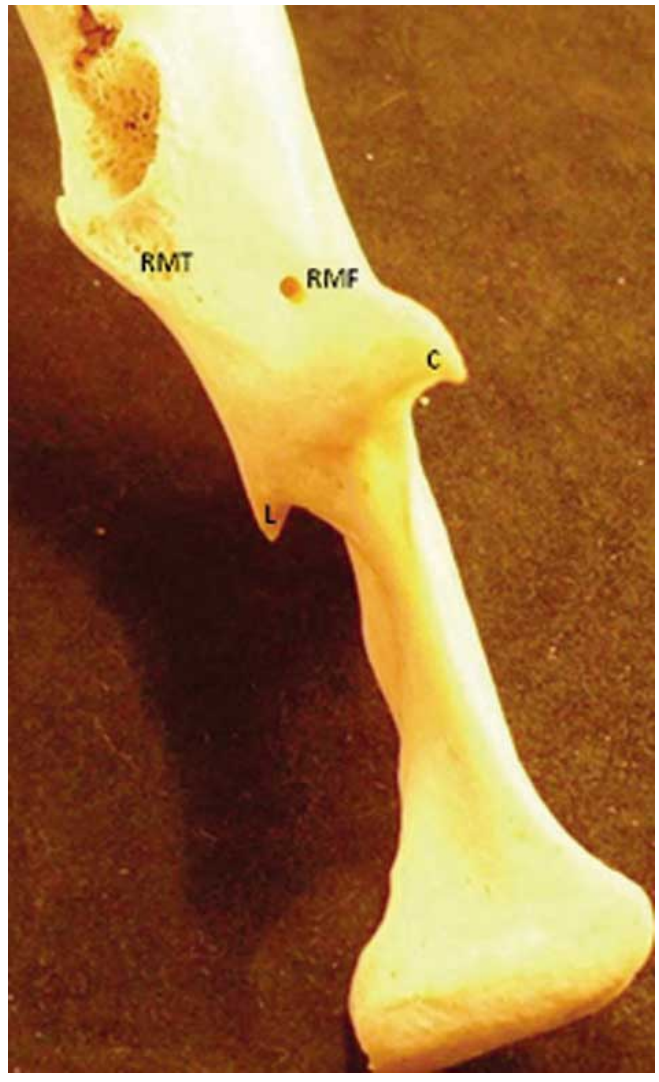

Fig. 5. Right retromandibular foramen in the mandible of a 62-year-old male individual. RMF: retromolar foramen L:mandibular lingula. RT: retromolar triangle. C: coronoid process. Taken from Suazo et al., 2008b.

d) Mylohyoid line: Corresponds to a rough bone elevation which runs obliquely the medial surface of the mandibular body, extending up to the lower third molar region. The mylohyoid line gives insertion to the mylohyoid muscle in most of its extension; nevertheless, in its posterior end, it serves as anchorage for the mylopharyngeal portion of the upper constrictor muscle of the pharynx. Superiorly, this line seems to extend the medial lip of the retromolar triangle.

e) Cortex and cancellous bone tissue: The characteristics of the cortex and cancellous bone tissue of the third molar region vary depending on the region being analyzed; in the retromolar triangle region, it presents a mean thickness of $1.77 \mathrm{~mm}$ (Suazo et al., 2008b), widening considerably towards the vestibule and thinning towards the lingual (Suazo et al., 2007).
Irrigation and drainage. The third molar region is irrigated mainly by collaterals of the lower alveolar and buccal arteries; additionally, collaterals of the lower masseteric, ascending palatine, mylohyoid, sublingual and submental arteries may participate (Castelli et al., 1975; Kawai et al., 2006).

The lower alveolar artery starts from the first segment of the maxillary artery in its infratemporal path. It originates the mylohyoid artery and then it introduces itself in the mandible through a mandibular foramen and completely runs the mandibular canal providing irrigation to the mandibular bone, to the posterior dentary pieces and to the dentary alveoli gingival process (Rouvière \& Delmas, 2005). The lower alveolar artery is an important tail vessel, in case of an injury it starts a heavy bleeding very difficult to stop in a non-hospital minor surgery room (Jensen, 1974). The complete ligation of the lower alveolar artery is necessary in surgical procedures such as mandibulectomy or partial mandibular section (Pickerill, 1949); in these cases, the supplementary irrigation provided by the submental, sublingual and buccal arteries allows the dentary pieces to continue healthy (Fuakami et al., 2011).

The buccal artery originates from the maxillary artery, it relates to the buccinator muscle irrigating it, and then it ramifies irrigating the region and the mucosa of the oral vestibule in the posterior region of the mandible. This artery is responsible for the collateral irrigation that penetrates the mandible through the retromolar foramen or through the retromolar triangle foraminas.

It is important to highlight the ascending palatine artery. This vessel originates from the facial artery in its cervical course, in its first portion. The ascending palatine artery follows a superomedial course, coming in contact with the styloglossus muscle and with the anterior pillar of the soft palate. It provides irrigation to the pharyngeal wall, to the muscles of the zone and to the tonsillar region. During a surgical extraction of the lower third molar, the commitment of the anterior pillar of the soft palate, either due to an excessive extension of the flap or to an accidental movement of the instrument, may affect the ascending palatine artery or its conmittant veins, causing heavy bleeding in the region, which may obstruct the isthmus of the fauces (Funayama et al., 1994).

The venous drainage of the lower third molar region follows the course of the arteries. Most of the blood is directed to the pterygoalveolar venous confluent; additionally, it may continue towards the veins of the oral cavity floor of the tonsillar region and of the pterygomandibular space (Rouvière \& Delmas).

The lymph drainage of the third molar region is in charge of multiple vessels which come together and accompanying the lower alveolar neurovascular axis. They mainly drain the submandibular and retropharynx lymph nodes, and also those found in the buccal region (Wang et al., 2011). In patients undergoing an infectious process of the region, it is possible to palpate a painful lymph node located against the basilar border, immediately anterior to the masseter muscle. 
Innervation. The lower third molar region receives innervation of the lower alveolar nerve, buccal nerve, lingual nerve, and the cervical plexus nerve. Additionally, it has the collaboration of the mental and mylohyoid nerves.

The lower alveolar nerve, posterior terminal ramu of the mandibular nerve, is a mixed nerve that runs the infratemporal region until it penetrates the mandibular foramen; in this course the nerve may present various variations, both in its relationships and its communications (Roy et al., 2002; Sandoval et al., 2009; Sharma et al., 2011). In the mandibular canal, it is accompanied by the homonymous arteries and veins, providing innervation to the bone, pulp of the posterior pieces, and finishes dividing itself, at the level of the mental foramen, in an incisive ramus that innervates the mandibular body anterior region and a mental ramus that innervates the soft parts of the region and the lower lip.

The lingual nerve is an anterior terminal ramus of the mandibular nerve, it is a sensitive nerve which also carries parasympathetic efferent fibers for the secretion of the sublingual and submandibular glands. It is a thick nerve whose mean diameter is $2.56 \mathrm{~mm}$ (Karakas et al., 2007), and runs the infratemporal region and descends in search of the submandibular hiatus, through which it penetrates the paralingual space where it emits its terminal rami; at the height of the lower second molar, the lingual nerve makes a medial curve to surround the submandibular conduct and emit its terminal rami (Chan et al., 2010a). In its course, the lingual nerve can establish communications with the mylohyoid nerve, which completes its innervation and explains a percentage of aneasthetic failures (Behnia et al., 2000; Kim et al., 2004).

The buccal nerve originates from the lateral division of the temporobuccal nerve and provides sensitive innervation to the tegument and mucosa of the buccal region and to the mandible posterior region gum. This nerve has a very superficial course in the lower third molar region, especially when it runs through the anaesthetic triangle zone of the posterosuperior surface; thus, it is only necessary to introduce the needle $1 \mathrm{~mm}$ and infiltrate anaesthesia to block the buccal nerve in the region.

The cervical plexus participates in the innervation of the region, its rami, the main one is the great auricular nerve, which, in a normal way, provide innervation to the mandibular triangle region. Its participation in the innervation of the lower third molar is not agreed upon, specially for the little presence of foraminas in the mandibular triangle region that these nerve threads may carry to the dentary piece. In spite of this discussion, the clinical use that intraoral infiltration in the mandibular triangle zone, of anaesthetic solution for blocking persistent pain in the third molar surgery, after the correct blocking of the buccal, lingual, and lower alveolar nerves, is not subject of doubt (Farache \& Alonso, 1969; Tong, 2000).

Main risk elements. Mandibular canal: The mandibular canal is a course that runs the mandible longitudinally from the mandibular foramen to the mental foramen; it has a lower alveolar neurovascular axis. In the lower third molar region, the mandibular canal acquires and ovoid shape with a maximum vertical diameter of $2.85 \mathrm{~mm}$ and a maximum horizontal diameter of $2.45 \mathrm{~mm}$. It is in this region where the canal has its maximum proximity to the dentary pieces. The mean distance of the canal to the vestibular cortex is $5.9 \mathrm{~mm}$, while the lingual cortex is 2.74 (Suazo et al., 2007b). There are three habitual presentations of the mandibular canal: sharp turn $(53.2 \%)$, soft curved exit (28.8\%), and straight path (17.4\%), The canal runs close to the third molar and then it moves away from the dentary pieces and finally moves close again at the level of the mental foramen (Ozturk et al., 2011).

The mandibular canal may be accompanied by accessory canals or it may be bifid or trifid. The accessory mandibular canal runs parallel to the main canal and has a prevalence of $1.7 \%$ (Suazo et al., 2011), presents an independent foramen from the mandibular foramen, and it is located in a superior plane in relation to the main canal.

The multiple mandibular canals start from the mandibular canal in its intra-bone course, they do not have their own foramen and may be found in a superior or inferior position in relation to the main canal. The literature describes a varied incidence, while the bifid canals are between 0.08\% to $75 \%$ (Grover \& Lorton, 1983; Naitoh et al., 2009), the trifid canals are scarse and there are only case reports estimating their prevalence at 2,2\% (Bogdán et al., 2006; Auluck et al., 2007).

Another important piece of information can be found in relation to the mandibular canal, called Conduct of Serres or paramandibular canal. This formation has been generally considered as an embryonic formation, meant to provide venous irrigation and drainage for deciduous dentition, for which it has been considered an anatomical variation in adults. These concepts have been discussed. Suazo et al. (2009), indicated that the prevalence of the conduct of Serres was $100 \%$ in mandibles of children between 0 and 2 years of age, $42.6 \%$ in adults (Fig. 6); while RodriguezVasquez et al. (2011), indicated that the conduct of Serres seems to be a venous drainage route in the process of ossification of the mandible, whose development is independent of dentary germs. 


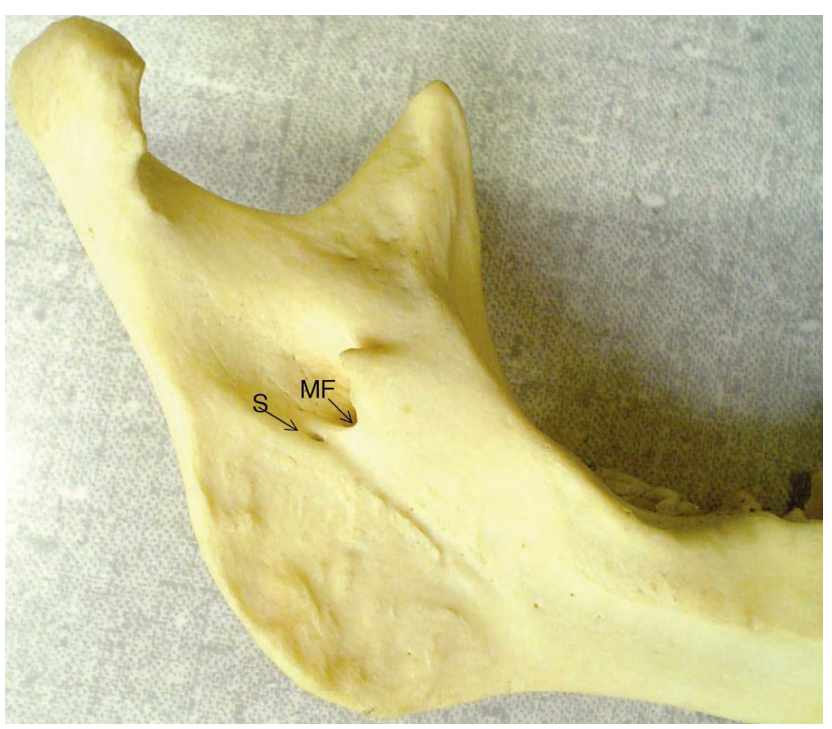

Fig. 6. Male mandible of 40 years old, medial view. $\mathrm{S}=$ Serres's canal; MF=Mandibular foramen. Taken from Suazo et al., 2009.

Lingual nerve: In its course, at the level of the submandibular hiatus, the lingual nerve makes a close approach to the third molar region, located at this level immediately under the oral cavity floor mucosa, in average $3 \mathrm{~mm}$ apically to the alveolar ridge and $2 \mathrm{~mm}$ medially from the lingual cortex (Fig. 7) although in a high percentage the nerve may be found on the alveolar ridge, immediately under the mucosa, therefore, it is of great importance as an element of risk in surgical extraction of the lower third molar, in fact it is estimated that $2 \%$ of these interventions cause some kind of injury to the lingual nerve (Gregg, 1992). These anatomical studies show that in between $57.4 \%$ and $62 \%$ of the cases the lingual nerve is in immediate contact with the lingual cortex medial to the retromolar triangle (Kiesselbach \& Chamberlain, 1984; Holzle $\&$ Wolff, 2001). Clinically, the position of the molar deep impaction, as well as linguoversion constitute the main risk factors for the injury of the lingual nerve during surgical extraction of the third molar (Akadiri et al., 2009), thus, its evaluation is necessary in pre-surgery planning (Chan et al., 2010b). When there are injuries of the lingual nerve, the sensitive, secreting and tasting functions are altered; these may be partially compensated by the communications that the lingual nerve establishes with the mylohyoid nerve (Kim et al.; Sassoli et al., 2007; Potu et al., 2009)

Retromolar canal: It is a variable structure, but when it is present it is a risk to be considered, especially in patients carriers of blood dyscrasias. The retromolar foramen and canal have anastomotic vessels that communicate venous and arterial circulation with lower alveolar vessels. The lesion of these structures can cause post-operatory haematomas and bleeding and their presence should be part of the imaging assessment protocol.

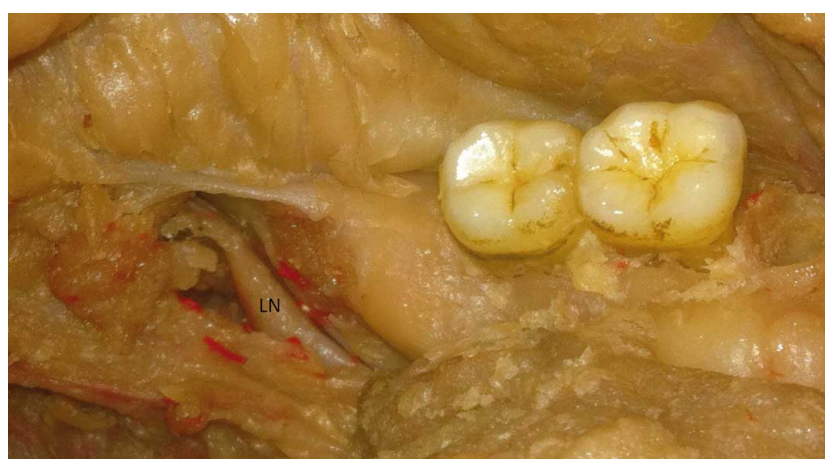

Fig. 7. Photograph of the left lower third molar region, male adult corpse. The mucosa has been opened and the relation between the lingual nerve and the region. $\mathrm{LN}=$ lingual nerve.

CONCLUSION. The low third molar region has great importance in the odontostomatological practice due to the prevalence of the pathological processes and complications related to the development and evolution of the third molar involved in the practice. This is the reason why this region is subject of a great number of surgical procedures with the possibility of causing injuries to some of the risk elements of the zone.

Despite the importance that this region has for Odontology, it has not been considered as a topological region by classical anatomy or by anatomical terminology. With the present topological demarcation, the elements of the third molar region should be included in the gingivoalveolodentary, paralingual space, massetericparotid, buccal, pterygopharyngeal or tonsilar regions. This is not a criterion being applied; therefore, a proposal has been presented for thesystematization of the description of the lower third molar region.

SUAZO, I. Región del tercer molar inferior. Int. J. Morphol., 30(3):970-978, 2012.

RESUMEN: La región del tercer molar inferior es una región importante para la práctica odontoestomatológica, en ella se presenta una gran cantidad de procesos patológicos relacionados con el desarrollo y erupción del tercer molar, por lo que se practican un gran número de intervenciones quirúrgicas. No obstante su importancia, esta región no se encuentra considerada en la terminología anatómica ni descrita en la anatomía topográfica y a pesar de la gran cantidad de estudios que analizan la anatomía quirúrgica de la región, es necesario sistematizar la descripción de sus límites, planos, contenidos, elementos de riesgo, puntos de reparo, etc., es por ello que el propósito de este artículo es revisar los conceptos modernos relacionados con la anatomía quirúrgica de la región del tercer molar inferior y proponer una descripción basada en estos conceptos.

PALABRAS CLAVE: Tercer molar; Nervio lingual; Nervio alveolar inferior; Canal mandibular; Cirugía oral. 


\section{REFERENCES}

Abe, S.; Iida, T.; Ide, Y.; \& Saitoh, C. An anatomical study of a muscle bundle separated from the medial pterygoid muscle. Cranio, 15(4):341-4, 1997.

Akadiri, O. A.; Fasola, A. O. \& Arotiba, J. T. Incidence and risk factors for nerve injuries in mandibular third molar surgery. Niger J. Med., 18:402-8, 2009.

Arbree, N. S.; Yurkstas, A. A. \& Kronman, J. H. The coronomaxillary space: literature review and anatomic description. J. Prosthet. Dent., 57:186-90, 1987.

Auluck, A.; Pai, K. M. \& Mupparapu, M. Multiple mandibular nerve canals: radiographic observations and clinical relevance. Report of 6 cases. Quintessence Int., 38:781-7, 2007.

Azaz, B. \& Lustmann, J. Anatomical configurations in dry mandibles. Br. J. Oral Surg., 11(1):1-9, 1973.

Behnia, H.; Kheradvar, A. \& Shahrokhi, M. An anatomic study of the lingual nerve in the third molar region. J. Oral Maxillofac. Surg., 58:649-51, 2000.

Bogdán, S.; Pataky, L.; Barabás, J.; Németh, Z.; Huszár, T. \& Szabó, G. Atypical courses of the mandibular canal: comparative examination of dry mandibles and x-rays. J. Craniofac. Surg., 17:487-91, 2006.

Castelli. W. A.; Nasjleti, C. E. \& Diaz-Perez, R. Interruption of the arterial inferior alveolar flow and its effects on mandibular collateral circulation and dental tissues. J. Dent. Res., 54:708-15, 1975.

Celebic, A.; Valentic-Peruzovic, M.; Kraljevic, K.; \& Brkic, H.. A study of the occlusal plane orientation by intra-oral method (retromolar pad). J. Oral Rehabil., 22(3):233-6, 1995.

Chan, H. L.; Benavides, E.; Yeh, C. Y.; Fu, J. H.; Rudek, I. E. \& Wang, H. L. Risk assessment of lingual plate perforation in posterior mandibular region: a virtual implant placement study using conebeam computed tomography. J. Periodontol., 82:129-35, 2010a.

Chan, H. L.; Leong, D. J.; Fu, J. H.; Yeh, C. Y.; Tatarakis, N. \& Wang, H. L. The significance of the lingual nerve during periodontal/ implant surgery. J. Periodontol., 81:372-77, 2010b.

Fakhry, A. The mandibular retromolar area as a donor site in maxillofacial bone grafting: surgical notes. Int. J. Periodontics Restorative Dent., 31:275-83, 2011.

Farache, S. \& Alonso, N. Contribution of the cervical plexus to the innervation of the mandible. Rev. Asoc. Odontol. Argent., 57:76-8, 1969.

Figún, M. \& Garino, R. Anatomía Odontológica Funcional y Aplicada. $2^{\mathrm{a}}$ ed. Buenos Aires, El Ateneo, 2001.

Fuakami, K.; Shiozaki, K.; Mishima, A.; Shimoda, S.; Hamada, Y. \&
Kobayashi, K. Detection of buccal perimandibular neurovascularisation associated with accessory foramina using limited cone-beam computed tomography and gross anatomy. Surg. Radiol. Anat., 33:141-6, 2011.

Funayama, M.; Kumagai, T.; Saito, K. \& Watanabe, T. Asphyxial death caused by postextraction hematoma. Am. J. Forensic. Med. Pathol., 15(1):87-90, 1994.

Gregg, J. Surgical management of lingual nerve injuries. Oral Maxillofac. Surg. Clin. Am., 4(2):417-24, 1992.

Grover, P. S. \& Lorton, L. Bifid mandibular nerve as a posible cause of inadequate anesthesia in the mandible. J. Oral Maxillofac. Surg., 41:177-9, 1983.

Holzle, F. W. \& Wolff, K. D. Anatomic position of the lingual nerve in the mandibular third molar region with special consideration of an atrophied mandibular crest: an anatomical study. Int. J. Oral Maxillofac. Surg., 30:333-8, 2001.

Jensen, S. Hemorrhage after oral surgery. An analysis of 103 cases. Oral Surg. Oral Med. Oral Pathol., 37(1):2-16, 1974.

Karakas, P.; Zel, M. \& Koebke, J. The relationship of the lingual nerve to the third molar region using radiographic imaging. Br. Dent. J., 203 (1): 29-31, 2007.

Kawai, T.; Sato, I.; Yosue, T.; Takamori, H. \& Sunohara, M. Anastomosis between the inferior alveolar artery branches and submental artery in human mandible. Surg. Radiol. Anat., 28(3):308-310, 2006.

Khoury, J. \& Townsend, G. Neural blockade anaesthesia of the mandibular nerve and its terminal branches: rationale for different anaesthetic techniques including their advantages and disadvantages. Anesthesiol. Res. Pract., 2011:307-423, 2011.

Kiesselbach, J. E. \& Chamberlain, J. G. Clinical and anatomic observations on the relationship of the lingual nerve to the mandibular third molar region. J. Oral Maxillofac. Surg., 42:565$7,1984$.

Kim, S.Y.; Hu, K. S.; Chung, I. H.; Lee, E.W. \& Kim, H. J. Topographic anatomy of the lingual nerve and variations in communication pattern of the mandibular nerve branches. Surg. Radiol. Anat., 26:128-35, 2004.

Kodera, H. \& Hashimoto, I. A case of mandibular retromolar canal: elements of nerves and arteries in this canal. Kaibogaku Zasshi, 70(1):23-30, 1995.

Libersa, J. C.; Francke, J. P.; Boudin, G.; Goudaert, M. \& Libersa, C. Anatomical basis for the surgical approach to the dental roots. Anat. Clin., 3:221-7, 1982.

López, F. B.; Suazo, G. I.; Cantín, L. M. \& Sandoval, M. C. Biomethrics study of the retromolar pad. Int. J. Odontostomat., 2(1):22-5, 2008.

McCrorie, J. W. \& Hall, D. C. A Histological Investigation of the Retromolar and Pear-Shaped Pad. Dent. Pract. Dent. Rec., 15:2379, 1965. 
Muto, T. \& Kanazawa, M. Mandibular reconstruction using the anterior part of the ascending ramus: Report of two cases. J. Oral Maxillofac. Surg., 55:1152, 1997.

Naitoh, M.; Hiraiwa, Y.; Aimiya, H. \& Ariji, E. Observation of bifid mandibular canal using cone-beam computerized tomography. Int J. Oral Maxillofac. Implants, 24:155-9, 2010.

Nakayama, Y.; Aoki, Y.; Fujita, H. \& Saigusa, K. Simple methods of forced oral opening for cadavers oriented to causes of fixed mandible. Nihon Hoigaku Zasshi, 52:202-6, 1998.

Narayana Nayak, U. A.; Ahmed, W. N., Bhat, J. G. \& Devaiah, B. A. The retromolar foramen and canal in south Indian dry mandibles. Eur. J. Anat., 6:141-6, 2002.

Ogawa, T.; Koyano, K. \& Suetsugu, T.. The relationship between inclination of the occlusal plane and mandible closing path. $J$. Prosthet. Dent., 76(6):576-80, 1996.

Ozturk, A., Potluri, A. \& Vieira, A. R. Position and course of the mandibular canal in skulls. Oral Surg. Oral Med. Oral Pathol. Oral Radiol. Endod., 2011 Epub.

Peron, J. M. Accidents d'evolution des dents de sagesse. EMC Dentisterie, 1:147-58, 2004.

Petruzzelli, G. J.; Knight, F. K.; Vandevender, D.; Clark, J. I. \& Emami, B. Posterior marginal mandibulectomy in the management of cancer of the oral cavity and oropharynx. Otolaryngol. Head Neck Surg., 129(6):713-9, 2003.

Pickerill, H. P. Ligation of the mandibular (inferior dental) artery. $B r$. Med. J., 1:527, 1949.

Potu, B. K.; Pulakunta, T.; Ray, B.; Rao, M. S.; Bhat, K. M.; D'Silva, S. S. \& Nayak, S. R. Unusual communication between the lingual nerve and mylohyoid nerves in a South Indian male cadaver: its clinical significance. Rom. J. Morphol. Embryol., 50:145-46, 2009.

Rodríguez-Vázquez, J. F.; Verdugo-López, S. \& Murakami, G. Venous drainage from the developing human base of mandible including Meckel's cartilage: the so-called Serres' vein revisited. Surg. Radiol. Anat., 33(7):575-81, 2011.

Rouvière, H. \& Delmas, A. Anatomía Humana: Descriptiva, Topográfica y Funcional. 11 a ed. Barcelona, Masson, 2005.

Roy, T. S.; Sarkar, A. K. \& Panicker, H. K. Variation in the origin of the inferior alveolar nerve. Clin. Anat., 15:143-7, 2002.

Sandner, M.O. Tratado de Cirugía oral y Maxilofacialo. Introducción básica a la enseñanza. Ed. AMOLCA, México, 2007.

Sandoval, M. C.; Suazo, G. I.; Cantín, L. M. \& López, F. B. Pilot study of the inferior alveolar nerve block anesthesia via the retromolar triangle in patients of 40 to 60 years. Int. J. Odontostomat., 2(1):8-13, 2008.

Sandoval, M. C; López, F. B. \& Suazo, G. I. An unusual relationship between the inferior alveolar nerve, lingual nerve and maxillary artery. Int. J. Odontostomat., 3(1): 51-53, 2009.
Sassoli, F. V. P., Rodriguez, F. O. A., Matamala F., Communication between the mylohyoid and lingual nerves: clinical implications, Int. J. Morphol., 25(3):561-4, 2007.

Schejtman, R.; Devoto, F. C. \& Arias, N. H. The origin and distribution of the elements of the human mandibular retromolar canal. Arch. Oral Biol., 12(11):1261-8, 1967.

Senthil-Kumar, S. \& Kesavi, D. A Study on the incidence of Retromolar Foramen and Canal in Indian Dried Human Mandibles and its Clinical Significance. Int. J. Anat. Sci., 1:14-6, 2010.

Sharma, A.; Vohra, H.; Singh, P. \& Sood, V. Unusual origin and variation in topographical relation of inferior alveolar nerve in the left infratemporal region. J. Indian Med. Assoc., 109:96-8, 2011.

Suazo, I.; Cantín, M. \& Zavando, D. Inferior alveolar nerve block anesthesia via retromolar triangle, an alternative for patients with blood discrasias. Med. Oral Pathol. Oral Cir. Bucal, 13(1):E43-7, 2008a.

Suazo, G. I. C.; Morales, H. C. A.; López, C. M. G. \& Zavando, M. D. A Aspectos biométricos del canal mandibular. Int. J. Morphol., 25(4):805-10, 2007b.

Suazo, G. I. C.; Zavando, M. D. A. \& Cantin, L. M. Retromolar canal and foramen prevalence in driedmandibles and clinical implications. Int. J. Odontostomat., 2(2):183-7, 2008b.

Suazo, G. I. C.; Zavando, M. D. A. \& Smith, R. L. Is the conduct of Serres an anatomical variation in adults? Int. J. Morphol., 27(1):437, 2009.

Suazo, G. I.; Cantín, L. M.; López, F. B.; Valenzuela, U. V. \& Valenzuela, R. R. Morphometric study of the retromolar triangle. Int. J. Odontostomatol., 1(2):119:22, 2007a

Suazo, G. I.; Zavando, M. D. \& Cantín L. M. Canal mandibular accesorio: análisis de su prevalencia y aspecto imagenológico. $A v$. Odontostomat., 27(2):85-90, 2011.

Taieb, F. \& Carpentier, P. Anatomy of the maxillary and mandibular retromolar area: effect on complete dentures. 2. The mandibular retromolar region. Cah. Prothese, 67:112-9, 1989.

Tong, D. C. The great auricular nerve: a case report and review of anatomy. N. Z. Dent J., 96:57, 2000.

Wang, Y.; Ow, T. J. \& Myers. J. N. Pathways for cervical metastasis in malignant neoplasms of the head and neck region. Clin. Anat., 18, 2011.

Correspondence to:

Prof. Dr. Iván Suazo G.

Faculty of Medicine

Universidad Diego Portales

CHILE

E-mail: ivan.suazo@udp.cl

Received: 18-06-2012

Accepted: 19-06-2012 